\title{
PROKLAMASI 17 AGUSTUS 1945: REVOLUSI POLITIK BANGSA INDONESIA
}

\author{
Haryono Rinardi
}

\author{
Departemen Sejarah Fakultas Ilmu Budaya \\ Universitas Diponegoro
}

Alamat korespondensi:haryono_rinardi@undip.ac.id

Diterima/ Received: 7 Oktober 2010; Disetujui/ Accepted:31 Oktober 2017

\begin{abstract}
This simple article examines on questions of the importance of the Indonesian independence proclamation on 17 August 1945 for Indonesian people, especially based on its legal validity. To answer legal issues along with the Indonesian independence proclamation event, it is necessary to disclose the advance of the proclamation event, so that it can be used as basis answer. This study uses literature method for examining the problems. Therefore, based on this review, this article formulates that the idea of Indonesian independence was formal and legally acquired through long struggle process, it was not "reward' as compensation for colonial practices which took place at the time.
\end{abstract}

Keywords: Independence Proclamation; Revolution; Politik.

\begin{abstract}
Abstrak
Artikel sederhana ini membahas persoalan arti penting Proklamasi Kemerdekaan 17 Agustus 1945 bagi bangsa Indonesia, terutama berdasar pada keabsahannya dari segi hukum. Untuk menjawab persoalan hukum yang menyertai peristiwa Proklamasi Kemerdekaan RI tersebut, maka perlu diungkap terlebih dahulu latar belakang peristiwa sehingga dapat dijadikan landasan untuk menjawab pertanyaan tersebut. Kajian ini menekankan pada penggunaan literatur sebagai metode utama untuk menelaah persoalan. Oleh karena itu, berdasar pada penelaahan tersebut, artikel ini merumuskan bahwa gagasan kemerdekaan Indonesia secara legal formal diperoleh melalui proses perjuangan yang panjang, bukan merupakan 'hadiah' atas praktik kolonialisasi yang berlangsung saat itu.
\end{abstract}

Kata Kunci: Proklamasi Kemerdekaan; Revolusi; Politik.

\section{PENDAHULUAN}

Salah satu babagan penting dalam perjalanan sejarah bangsa Indonesia adalah Proklamasi Kemerdekaan 17 Agustus 1945. Peristiwa itu menjadi tonggak penting bangsa Indonesia, karena dengan proklamasi tersebut bangsa Indonesia menyatakan kemerdekaan dirinya sehingga sejajar dengan bangsa-bangsa lain di dunia. Kejadian pada Jumat tanggal 17 Agustus 1945 itu bukan berdiri sendiri secara tunggal, tetapi merupakan puncak dari rangkaian kejadian yang telah terjadi sebelumnya. Proklamasi oleh sebagain orang dianggap sebagai titik kulminasi perjuangan panjang bangsa Indonesia dalam mencapai kemerdekaannya. Dengan cara pandang seperti itu, berarti masuk akal kiranya apabila Proklamasi 17 Agustus 1945 merupakan bagian dari rangkaian panjang perjuangan bangsa Indonesia dalam mencapai kemerdekaannya. Hal itu disebabkan 
kemerdekaan Indonesia tidak didapat sebagai hadiah dari bangsa lain. Kemerdekaan Indonesia melalui Proklamasi 17 Agustus 1945 adalah hasil perjuangan panjang bangsa Indonesia untuk menuntut kemerdekaannya lepas dari belenggu penjajahan bangsa asing.

Argumentasi itu didasarkan atas perjuangan panjang bangsa Indonesia untuk merebut kemerdekaannya. Berbagai perjuangan bersenjata telah dilakukan oleh bangsa Indonesia untuk menolak dominasi dan kekuasaan asing di wilayah Nusantara. Sepanjang lebih dari tiga abad terjadi konflik berdarah antara penguasa lokal Nusantara dengan pihak asing. Konflik terjadi karena penguasa lokal Nusantara menolak dominasi dan kekuasaan asing di wilayah Nusantara. Pada sisi lainnya, pihak asing mencoba memaksakan kehendaknya untuk mendapatkan kekayaan alam dan tenaga kerja bangsa Indonesia. Konflik semacam itu terjadi semenjak kedatangan Barat di Nusantara, mulai dari ujung barat sampai ujung timur Indonesia. Semuanya itu menunjukkan perjuangan dan upaya bangsa Indonesia untuk melepaskan diri dari belenggu penjajahan dan upaya untuk menempatkan dirinya sejajar dengan bangsa lain.

Artikel ini membahas persoalan arti Proklamasi Kemerdekaan 17 Agustus 1945 bagi Bangsa Indonesia, terutama dari keabsahannya dari segi hukum. Oleh karena itu, permasalahan yang hendak dikemukakan dalam artikel ini adalah bagaimana hubungan fungsional antara Proklamasi 17 Agustus 1945 dan keabsahannya dari segi hukum positif. Persoalan keabsahan Proklamasi 17 Agustus 1945 sangat penting berkaitan dengan perspektif hukum positif. Dalam perspektif tersebut sebuah persoalan harus mempunyai dasar hukum yang benar, karena segala sesuatunya dapat dianggap tidak sah atau illegal jika tidak mempunyai dasar hukum. Untuk menjawab pertanyaan itu, maka akan dijawab terlebih dahulu latar belakang munculnya Prokalamasi 17 Agustus 1945, sehingga dapat dijadikan landasan untuk menjawab pertanyaan tersebut.
Oleh karena itu, permasalahan yang dikemukakan dalam makalah ini adalah bagaimana hubungan fungsional antara Proklamasi 17 Agustus 1945 dan keabsahannya dari segi hukum postif. Persoalan keabsahan Proklamasi 17 Agustus 1945 sangat penting berkaitan dengan perspektif hukum positif. Dalam perspektif tersebut sebuah persoalan harus mempunyai dasar hukum yang benar, karena segala sesuatunya dapat dianggap tidak sah atau illegal jika tidak mempunyai dasar hukum.

\section{PPKI}

Pada 7 Agustus 1945 atas persetujuan Komando Tertinggi Jepang Jendral Terauchi di Saigon dibentuk Panitia Persiapan Kemerdekaan Indonesia (PPKI) atau dalam bahasa Jepangnya Dokuritsu Tyumbi Iinkai. Soekarno diangkat sebagai ketua, sedangkan M. Hatta bertindak sebagai wakil ketua. PPKI ini mulai bekerja pada tanggal 9 Agustus 1945. Tugasnya adalah menyelesaikan soal-soal yang berhubungan dengan kemerdekaan, terutama mengenai UUD yang rancangannya telah ada, dan akan diserahkan kepada PPKI untuk diterima dan disahkan (Juniarto, 1996: 25; The Liang Gie, 1993: 26). Para anggota PPKI diizinkan untuk melakukan kegiatannya menurut pendapat dan kesanggupan bangsa Indonesia sendiri, tetapi mereka diwajibkan memperhatikan hal-hal sebagai berikut. (1) Syarat pertama untuk mencapai kemerdekaan ialah menyelesaikan perang yang sekarang sedang dihadapi oleh bangsa Indonesia; karena itu bangsa Indonesia harus mengerahkan tenaga sebesar-besarnya, dan bersama-sama dengan pemerintah Jepang meneruskan perjuangan untuk memperoleh kemenangan akhir dalam Perang Asia Timur Raya. (2) Negara Indonesia itu merupakan anggota lingkungan kesemakmuran bersama di Asia Timur Raya, maka cita-cita bangsa Indonesia itu harus disesuaikan dengan cita-cita pemerintah Jepang yang bersemangat Hakko-Iciu (Poesponegoro \& Notosusanto, 1992:77). 
PPKI ini semula jumlah anggotanya hanya 21 orang, namun kemudian atas usul Soekarno panitia itu ditambah lagi sehingga jumlahnya menjadi 27 orang termasuk ketua dan wakilnya (Mahfud MD, 1993: 49). Menurut rencana PPKI akan dilantik pada tanggal 18 Agustus 1945, sedangkan kemerdekaan Indonesia akan disahkan oleh pemerintah Jepang pada tanggal 24 Agustus 1945 (The Liang Gee, 1993: 27). Rencana untuk kemerdekaan pada 24 Agustus itu, pada akhirnya berbeda sama sekali. Sekali lagi medan Perang Pasifik ikut memengaruhi kondisi sosial politik di Indonesia. Pemboman Hiroshima dan Ngasaki oleh Amerika Srikat dan penyerbuan pasukan Uni Sovyet ke Manchuria yang dikuasai Jepang besar pengaruhnya atas ketegaran Jepang terhadap perang pasifik. Dengan kondisi Perang Pasifik yang sudah sangat kritis tersebut, maka pada 15 Agustus 1945 Jepang menyerah tanpa syarat kepada Sekutu, suatu kondisi yang sangat tidak diduga sama sekali oleh para pemimpin Bangsa Indonesia saat itu.

Kesempatan itu segera dimanfaatkan kelompok pemuda dan gerakan bawah tanah anti Jepang. Sekelompok mahasiswa kedokteran yang memonitor keadaan politik internasional melalui pemancar gelap mengetahui menyerahnya Jepang kepada Sekutu. Mereka segera menghubungi tokoh-tokoh muda revolusioner, seperti Wikana, Sukarni, dan Chairul Saleh. Mereka menginginkan kemerdekaan segera diproklamasikan lepas sama sekali dari pengaruh Jepang (Yuniarti, 2003: 36). Sutan Syahrir termasuk dalam tokoh yang menolak kemerdekaan Indonesia dikaitkan dengan janji Jepang. Syahrir bahkan merupakan tokoh pertama yang mendesak diproklamasikannya kemerdekaan oleh Soekarno dan Hatta tanpa menunggu janji Jepang. Kelompok pemuda menolak kemerdekaan yang berbau Jepang. Dengan pandangan yang seperti itu mereka juga menolak kemerdekaan yang diproklamasikan oleh PPKI, karena PPKI merupakan buatan Jepang. Dalam hal ini terjadi perbedaan pendapat dengan tokoh-tokoh BPUPKI dan PPKI. M. Hatta berpendapat bahwa soal kemerdekaan Indonesia datangnya dari pemerintah Jepang atau dari hasil perjuangan bangsa Indonesia sendiri tidaklah menjadi soal karena Jepang sudah kalah. Bangsa Indonesia saat itu harus menghadapi sekutu yang akan berusaha mengembalikan kekuasaan Belanda di Indonesia. Oleh karena itu untuk memproklamasikan kemerdekaan Indonesia diperlukan suatu revolusi yang terorganisasi. Soekarno dan Hatta ingin membicarakan masalah pelaksanaan proklamasi kemerdekaan dalam rapat PPKI pada tanggal 16 Agustus 1945, sehingga dengan demikian tidak menyimpang dari ketentuan pemerintah Jepang (Poesponegoro \& Notosusanto, 1992: 79).

Situasi yang berkembang di Indonesia, khususnya di Jakarta saat itu menegangkan. Kelompok pemuda menuntut Soekarno segera memproklamasikan kemerdekaan Indonesia yang terlepas dari pengaruh Jepang, sedangkan tokohtokoh tua dalam BPUPKI-PPKI dengan motor Soekarno dan Hatta menginginkan proklamasi dapat dilakukan sesuai dengan hasil keputusan rapat sidang PPKI tanggal 16 Agustus 1945 (Yuniarti, 2003: 37). Apalagi saat itu anggota PPKI sudah mulai berdatangan ke Jakarta. Mereka takut terjadi pertumpahan darah. Sebaliknya, kelompok pemuda berpendapat bahwa partumpahan darah adalah risiko yang tidak bisa dihindari. Kemungkinan pertumpahan darah dapat terjadi sebab Jepang diminta menjaga status quo di wilayah yang diduduki, sehingga proklamasi bisa dianggap sebagai suatu pelanggaran (Sagimun MD, 1989: 277).

Dalam posisi yang genting itu, kelompok pemuda mengadakan rapat di Lembaga Bakteriologi di Pegangsaan Timur pada 15 Agustus 1945 pukul 20.30 waktu Jawa zaman Jepang. Keputusan rapat yang dipimpin Chairul Saleh menegaskan bahwa kemerdekaan Indonesia adalah hak dan soal rakyat Indonesia sendiri, tidak dapat digantungkan pada orang lain dan kerajaan lain. Segala ikatan dan hubungan dengan janji kemerdekaan dari Jepang harus diputuskan dan sebaliknya diharapkan diadakannya perundingan dengan Soekarno dan Hatta agar supaya mereka diikutsertakan menyatakan Proklamasi (Malik, 1962:35). Hasil rapat itu kemudian disampaikan 
kepada Soekarno dan Hatta di kediamannya masing-masing. Sekali lagi Soekarno dan Hatta dengan tegas menolak permintaan itu, walaupun hal itu sempat menimbulkan ketegangan ketika Wikana (wakil kelompok pemuda yang bertugas menyampaikan hasil rapat kepada Soekarno) menyatakan akan terjadi pertumpahan darah jika keinginan mereka tidak dilaksanakan Poesponegoro \& Notosusanto, 1992:80). Mendengar ancaman itu Soekarno bukannya takut justru balik menggertak dengan mempersilahkan para pemuda untuk membunuhnya saat itu juga. Soekarno juga mengatakan bahwa dia tidak mau memproklamasikan kemerdekaan pada saat itu karena terikat dengan kedudukannya sebagai Ketua PPKI, sehingga menurutnya soal proklamasi kemerdekaan harus ditanyakan kepada wakil-wakil PPKI (Adams, 1966:316-317).

Gagalnya permintaan kelompok pemuda agar Soekarno dan Hatta memproklamasikan kemerdekaan yang terlepas dari Jepang, segera mendorong mereka untuk mengadakan rapat lagi. Kali ini rapat diadakan pukul 00.30 waktu Jawa zaman Jepang (atau kira-kira pukul 24.00) menjelang 16 Agustus 1945. Selain dihadiri oleh pemuda-pemuda yang sebelumnya terlibat dalam rapat di Lembaga Bakteriologi, rapat itu juga dihadiri oleh Sukarni, Jusuf Kunto, dr. Muwardi dari Barisan Pelopor dan Shodanco Singgih dari Daidan Peta JakartaSyu. Dalam rapat itu diputuskan bahwa Soekarno dan Hatta harus disingkirkan ke luar kota dengan tujuan menjauhkan mereka dari segala pengaruh Jepang Poesponegoro \& Notosusanto, 1992: 81).

Rencana itu kemudian dilakukan dengan membawa Soekrno dan Hatta ke Rengasdengklok pada pukul 04.30 waktu Jawa zaman Jepang (sekitar 04.00). Rencana itu berjalan lancar karena diperolehnya dukungan berupa perlengkapan tentara Peta dari Cudanco Latief Hendraningrat yang saat itu menggantikan Daidanco Kasman Singodimedjo yang bertugas ke Bandung. Pelaksanaannya dipimpin oleh dr. Soetjipto dari Markas Peta Jaga Monyet dan Soekarni (Yuniarti, 2003: 39). Sehari penuh Soekarno dan Hatta ada di Rengasdengklok. Rencananya para pemuda bermaksud untuk menekan mereka berdua agar segera memproklamasikan kemerdekaan terlepas dari ikatan dengan Jepang. Akan tetapi, wibawa mereka berdua sebagai tokoh senior pergerakan nasional membuat para pemuda penculiknya segan untuk melakukan penekanan.

Di Jakarta sendiri, Ahmad Subardjo dari golongan tua bertemu dengan Wikana dari kaum muda. Dalam pertemuan itu dicapai kesepakatan bahwa Proklamasi Kemerdekaan harus segera diadakan di Jakarta. Berdasar hal itu, Ahmad Subardjo bersama dengan sekretaris pribadinya Sudiro dengan diantar Jusuf Kunto pergi Rengasdengklok untuk menyemput Soekarno dan Hatta. Setelah rombongan Soekarno dan Hatta tiba kembali ke Jakarta, dengan terlebih dahulu kembali ke rumah masing-masing, mereka berdua menemui Mayor Jendral Nishimura untuk menjajagi sikapnya mengenai Proklamasi Kemerdekaan. Dalam pertemuan itu juga hadir Laksamana Maeda, Shigetada Nishijima dan Tomegoro Yoshizumi serta Miyoshi sebagai penterjemah. Dalam pertemuan Soekarno dan Hatta menekankan kepada Nishimura bahwa Jendral Terauchi telah menyerahkan pelaksanaan proklamasi kepada PPKI. Sementara itu, Nishimura menolak proklamasi kemerdekaan karena Jepang telah terikat untuk menjaga status quo di daerah yang didudukinya. Berdasar hal itu Nishimura melarang Soekarno dan Hatta mengadakan rapat PPKI dalam rangka melaksanakan proklamasi kemerdekaan (Hatta, 1970: 53-54).

Oleh karenna itu, diputuskan bahwa kemerdekaan Indonesia harus ditentukan oleh bangsa Indonesia sendiri, terlepas dari Jepang. Kemudian segera diadakan pertemuan di rumah Laksamana Maeda, seorang Kepala Kantor Perhubungan Angkatan Laut, yang dianggap cukup aman. Pertimbangan lainnya Laksamana Maeda mempunyai hubungan yang baik dengan Ahmad Subardjo dan para pemuda ya ng bekerja di kantornya (Notosusanto, 1976:10-11). Di ruang makan rumah itu dirumuskan naskah proklamasi Kemerdekaan Indonesia. Maeda sebagai tuan rumah mengundurkan diri dan tidur 
di lantai dua. Miyoshi orang kepercayaan Nishimura juga hadir bersama dengan Mbah Diro, B.M. Diah, dan Sukarni untuk menyaksikan Soekarno, Hatta, dan Ahmad Subardjo membahas perumusan Naskah Proklamasi Kemerdekaan Indonesia. Sementara itu, tokoh-tokoh lainnya baik golongan tua maupun kelompok pemuda menunggu di serambi muka. Soekarno yang menuliskan konsep Proklamasi pada secarik kertas, sedangkan M. Hatta dan Ahmad Subardjo menyumbangkan pikiran secara lisan (Notosusanto, 1976: 11). Akhirnya menjelang subuh Soekarno bertiga menemui mereka yang sudah menunggu di serambi muka. Pada saat itu, Soekarno mengajak mereka semua bersama-sama menandatangani naskah proklamasi selaku wakilwakil bangsa Indonesia. Saran itu diperkuat oleh M. Hatta, tetapi oleh Sukarni diusulkan bahwa yang menandatangani naskah Proklamasi cukup dua orang saja, yakni Soekarno-Hatta atas nama bangsa Indonesia. Usul itu juga disetujui oleh mereka yang hadir, sehingga Soekarno meminta kepada Sayuti Melik untuk mengetik naskah Proklamasi berdasar naskah tulisan tangan Soekarno, disertai dengan perubahan-perubahan yang telah disetujui (Poesponegoro \& Notosusanto, 1992:85).

Pada 17 Agustus 1945, akhirnya proklamasi kemerdekaan dilakukan di depan rumah Soekarno di Jalan Pegangsaan Timur No. 56, karena apabila dilakukan di lapangan Ikada dikhawatirkan dapat menimbulkan bentrokan antara rakyat dengan pihak militer Jepang. Usul itu disetujui dan pembacaan naskah Proklamasi Kemerdekaan Indonesia berlangsung di Pegangsaan Timur No 56 pada Jum'at, 17 Agustus 1945 pukul 10.30 waktu Jawa zaman Jepang (pukul 10.00) pada saat bulan puasa (Poesponegoro \& Notosusanto, 1992: 87).

Keesokan harinya pada 18 Agustus 1945, PPKI mengadakan sidang untuk pertama kalinya. Dalam Sidang itu berhasil ditetapkan UndangUndang Dasar (UUD) hasil rancangan Panitia Kecil di dalam Panitia Hukum Dasar, yang diketuai oleh Soepomo sebagai UUD bagi negara Indonesia. UUD ini kemudian dikenal sebagai
UUD 1945. Meskipun demikian, UUD 1945 tidak sama persis dengan rancangan UUD yang dibuat oleh Panitia Kecilnya Soepomo. Ada beberapa perbedaan, yaitu; (1) Kata Mukkaddimah diganti dengan kata Pembukaan; (2) Sila Pertama yang semula (dalam Piagam Jakarta) berbunyi: "KeTuhanan dengan kewajiban menjalankan syari'at Islam bagi pemeluk-pemeluknya" diganti dengan kalimat: "Ketuhanan Yang Maha Esa"; (3) Pasal 6 yang semula (dalam batang tubuh UUD) berbunyi: "Presiden ialah orang Indonesia asli yang beragama Islam", diganti dengan "Presiden ialah orang Indonesia asli"; (4) Pasal 28 yang semula (dalam batang tubuh UUD) berbunyi "Negara berdasarkan atas Ke-Tuhanan dengan kewajiban menjalankan syari'at Islam bagi pemeluk-pemeluknya" diganti dengan "Negara berdasarkan Ketuhanan Yang Maha Esa”; (5) (pasal ini kemudian menjadi Pasal 29) (Mahfud MD 1993: 52; Bahar, dkk., 1995: 414-415). (6) Wakil presiden yang semula dua diubah menjadi satu (Mahfud MD, 1993: 20).

PPKI dalam sidangnya itu selain memutuskan mengesahkan UUD 1945 sebagai UUD bagi Bangsa Indonesia, juga membuat keputusan penting lainnya. Keputusan penting itu adalah pengangkatan Soekarno dan M. Hatta masing-masing sebagai Presiden dan Wakil Presiden Indonesia. Selain itu, atas usul Soekarno dibentuk sebuah Komite Nasional yang mampu dikumpulkan dengan cepat pada masa-masa genting, karena anggota-anggota PPKI banyak yang akan meninggalkan Jakarta. Tugas komite itu adalah sebagai badan pembantu presiden (Bahar, 1995: 447), selama kondisi di Indonesia masih dalam kondisi darurat.

\section{PROKLAMASI: MAKNA DAN ARTINYA BAGI BANGSA INDONESIA}

Dengan diproklamasikan kemerdekaan Indonesia berarti bangsa Indonesia telah menyatakan kemerdekaannya secara formal, baik kepada dunia internasional maupun kepada Bangsa Indonesia sendiri, bahwa mulai saat itu Bangsa Indonesia telah merdeka. Merdeka berarti bahwa mulai saat 
itu bangsa Indonesia mengambil sikap menentukan nasibnya dan nasib tanah airnya dalam segala bidang (Joeniarto, 1996: 4). Pada sisi lain proklamasi kemerdekaan itu sekaligus juga pernyataan bahwa bangsa Indonesia telah cakap untuk mengurus rumah tangganya sendiri dan memberitahukan sudah menegakkan suatu negara nasional yang merdeka dan berdaulat. Keterangan kemerdekaan itu memulai "Fajar", bahwa Revolusi Indonesia telah mulai berjalan. Revolusi ini memusnahkan dan meruntuhkan keadaan yang lama dan memunculkan pembentukan negara dan masyarakat baru, negara dan masyarakat Indonesia (Yamin, 1982: 24). Dengan adanya proklamasi kemerdekaan bangsa Indonesia, maka mulai saat itu hanya berlaku tata hukum Indonesia, menggantikan tata hukum kolonial. Dengan proklamasi kemerdekaan itu, segala sesuatu yang berbau kolonial telah digantikan dengan sesuatu yang bersifat nasional.

Dengan kondisi itu berarti bangsa Indonesia telah memutuskan ikatan dengan tata hukum yang sebelumnya, baik tatanan hukum Hindia Belanda maupun tatanan hukum pendudukan Jepang (Joeniarto, 1996: 6). Hal itulah yang sesungguhnya menjadi tujuan dari proklamasi kemerdekaan bangsa Indonesia. $\mathrm{Hal}$ ini sesungguhnya wajar bagi sebuah negara yang merdeka. Sebuah negara merdeka haruslah mempunyai tatanan hukumnya sendiri, tidak mengikuti atau masih memakai tatanan hukum kolonial.

Proklamasi dengan demikian menjadi dasar hukum bagi pelaksanaan tatanan hukum yang baru. Proklamasi menjadi dasar hukum bagi berlakunya hukum nasional. Dengan demikian, segala macam peraturan, hukum, dan ketentuan yang berlaku dan akan berlaku di Indonesia dasar hukumnya adalah Proklamasi Kemerdekaan Indonesia tanggal 17 Agustus 1945. Dengan dasar itu, wajar apabila beberapa jam setelah Proklamasi PPKI mengesahkan UUD 1945 sebagai konstitusi bagi bangsa Indoneisa. Dalam titik inilah peranan proklamasi sebagai dasar hukum bagi berlakunya segala aturan, ketentuan, dan hukum yang berlaku di Indonesia terlihat jelas dan terbukti. Oleh karena itu, wajar bila Proklamasi Kemerdekaan Indonesia merupakan norma pertama daripada tata-hukum Indonesia (Joeniarto, 1996: 6).

Norma pertama atau ada pula yang menyebutnya sebagai norma dasar atau ada pula yang menyebutnya sebagai aturan dasar, sementara Prof. M. Yamin menyebutnya sebagai Mahasumber daripada segala aturan hukum. Dalam hal ini yang dimaksudkan sebagai norma dasar adalah norma/aturan/ketentuan hukum yang pertama adanya pada tata-hukum yang bersangkutan, oleh karena itu norma/aturan/ ketentuan ini menjadi dasar bagi berlakunya segala macam norma/aturan/ketentuan hukum yang lainnya. Dengan dasar pemikiran itu, maka dapat dikatakan bahwa norma pertama menjadi dasar bagi segala sumber hukum, atau ketentuan/ peraturan hukum lainnya. Segala macam ketentuan atau peraturan hukum yang terdapat dalam tata-hukum yang bersangkutan harus dapat dikembalikan kepada norma pertamanya. Dengan demikian, norma pertama ini tidak dapat dicari dasar hukumnya, karena dia sendiri sudah merupakan dasar hukum bagi segala macam norma atau aturan hukum yang berlaku dalam tata-hukum yang bersangkutan (Joeniarto, 1996: 7).

Ilmu hukum positif tidak akan dapat mencari dasar hukumnya, kekuatan berlakunya norma pertama. Akan tetapi, timbulnya norma pertama ini dapat dipelajari dengan pendekatan bidang ilmu lain, seperti filsafat, sosiologis, politis, sejarah, dan sebagainya. Dengan dasar pemikiran yang seperti itu, maka Proklamasi Kemerdekaan yang merupakan norma pertama bagai tata-hukum Indonesia dasarnya tidak akan dapat dicari dalam tata-hukum Jepang maupun Belanda. Hal ini mudah dimengerti sebab pada tata-hukum kolonial tentu saja tidak akan mungkin terdapat suatu ketentuan ataupun aturan yang memungkinkan bagi bangsa Indonesia untuk memproklamasikan kemerdekaannya (Joeniarto, 1996:8). Secara logika tidak mungkin dalam suasana kolonial untuk mengkampanyekan kemerdekaan bagi bangsa yang dikuasai oleh penguasa kolonial. Kondisi itu jelas nyata, karena 
kebebasan politik bagi warga bumiputera juga tidak akan diberikan oleh penguasa kolonial. Pada tingkat yang lebih rendah sekalipun pemerintah kolonial bahkan tidak memberikan tempat bagi kaum bumiputera untuk duduk dalam suatu badan perwakilan yang memungkinkannya untuk menyuarakan segala aspirasi politiknya secara resmi. Dalam suasana kolonial jelas tidak akan terdapat suatu kebebasan politik yang memungkinkan kaum bumiputera untuk mengutarakan segala tuntutan dan aspirasi politik, sehingga sangat jelas bahwa dalam periode kolonial tidak akan dapat ditemui adanya aturan yang memungkinkan bangsa Indonesia untuk memproklamasikan kemerdekaannya.

$$
\text { Dalam kenyataannya Proklamasi }
$$

Kemerdekaan adalah tingkatan penutup perjuangan kemerdekaan yang hampir 40 tahun bergolak di Indonesia. Pada sisi yang lain, Proklamasi Kemerdekaan menjadi permulaan atau titik awal pembelaan bagi Negara Merdeka Republik Indonesia. Dengan Proklamasi Kemerdekaan Indonesia, berkembanglah kekuasaan de jure di seluruh Kepulauan Indonesia dalam tangan dan rakyat dan pemerintah Indonesia. Proklamasi juga menjadi awal kekuasaan de facto sebagian-sebagian, menuju kekuasaan de facto seluruhnya di Kepulauan Indonesia. Berdasar Proklamasi Kemerdekaan terbentuklah Negara Republik Indonesia (Yamin, 1982: 25), yang berusaha mewujudkan segala citacita bangsa Indonesia.

\section{SIMPULAN}

Proklamasi Kemerdekaan 17 Agustus 1945 merupakan tonggak penting bangsa Indonesia. Melalui proklamasi itu bangsa Indonesia menyatakan kemerdekaan kepada semua bangsa di dunia. Hal yang tidak kalah pentingnya adalah dengan proklamasi itu, membuktikan bahwa kemerdekaan Indonesia diperoleh melalui usaha dan perjuangan bangsa Indonesia sendiri. Kemerdekaan Indonesia didapat bukan hadiah Jepang. Kemerdekaan Indonesia terlepas dari campur tangan Jepang. Hal itu juga menunjukkan bahwa bangsa Indonesia bukan merupakan pihak yang kalah dalam Perang Dunia II. Dalam kenyataannya, setelah Proklamasi Kemerdekaan 17 Agustus 1945 Bangsa Indonesia masih terlibat konflik dengan Jepang, seperti dalam peristiwa Pertempuran Lima Hari di Semarang. Dengan Proklamasi 17 Agustus 1945 menunjukkan bahwa bangsa Indonesia memiliki harga diri yang tinggi, bahkan lebih tinggi dibanding dengan banyak negara lain. Hal itu disebabkan kemerdekaan Bangsa Indonesia diperoleh dengan cara perjuangan berdarah yang menghabiskan banyak dana dan jiwa pejuang Indonesia. Dengan demikian tidak banyak negara di dunia yang kemerdekaannya diperoleh seperti yang dilakukan oleh bangsa Indonesia. Tercatat hanya Amerika Serikat, Aljazair, dan Vietnam yang kemerdekaannya diperoleh dengan cara perjuangan berdarah.

Proklamasi Kemerdekaan 17 Agustus 1945 menjadi awal bangsa Indonesia guna menegakkan hak asasinya sebagai bangsa yang setara dengan bangsa lain. Bersamaan itu, Proklamasi Kemerdekaan 17 Agustus 1945 juga menjadi sumber dari segala sumber hukum Bangsa Indonesia. Melalui proklamasi tersebut, mulailah hukum nasional Indonesia di bumi nusantara ini. Proklamasi menjadi landasan bagi dihapuskannya hukum kolonial, dan sekaligus sebagai permulaan untuk menggantinya dengan hukum yang lebih berpihak kepada manusia dan bangsa Indonesia. Dengan demikian, seharusnya Proklamasi 17 Agustus 1945 menjadi landasan hukum dan awal bagi kesejahteraan dan kemakmuran Bangsa Indonesia.

\section{REFERENSI}

Adams, Cindy (1966). Bung Karno Penyambung Lidah Rakyat Indonesia. Jakarta: Gunung Agung.

Bahar, Safroedin, dkk., ed. (1995). Risalah Sidang Badan Penyelidik Usaha-Usaha Persiapan Kemerdekaan Indonesia (BPUPKI) Panitia Persiapan Kemerdekaan 
Indonesia. Jakarta: Sekretariat Negara Republik Indonesia.

Hatta, Mohammad (1970). Sekitar Proklamasi 17 Agustus 1945. Jakarta: Tintamas.

Juniarto (1996). Sejarah Ketatanegaraan Republik Indonesia. Jakarta: Bumi Aksara.

Mahfud MD. (1993). Dasar dan Struktur Ketatanegaraan Indonesia. Yogyakarta: Penerbit UII Press.

Notosusanto, Nugroho (1976). Naskah Proklamasi yang Otentik dan Rumusan Pancasila yang Otentik. Jakarta: Pusat Sejarah ABRI.

Poesponegoro, Marwati Djoened \& Nugroho Notosusanto (1992). Sejarah Nasional Indonesia VI. Jakarta: Depdikbud RI.

Sagimun MD. (1989). Peranan Pemuda, Dari Sumpah Pemuda Sampai Proklamasi. Jakarta: Bina Aksara

Thee Liang Gie (1993). Pertumbuhan Pemerintah Daerah di Negara Republik Indonesia. Yogyakarta: Liberty.

Yamin, M. (1982). Proklamasi dan Konstitusi Republik Indonesia. Jakarta: Ghalia Indonesia.

Yuniarti, Rini D. (2003). BPUPKI, PPKI, Proklamasi Kemerdekaan RI. Jakarta: Penerbit Buku Kompas. 